\title{
Perceived vs. Actual Distance to Transit in Santiago, Chile
}

\author{
Diego Hernández, Ph.D. \\ Catholic University of Uruguay \\ Regina Witter, Ph.D. \\ Regional Government of Lausanne-Morges, Switzerland
}

\begin{abstract}
To plan public transport supply and to increase transit patronage, it is indispensable to be aware of people's perception of the actual supply, that is, how extensive and accurate people's knowledge is regarding the concrete features of transport supply, such as the locations of transit stops, timetables, and fare structures. This paper addresses the gap between the perceived and real distances to transit stops. The comparison between the real and perceived supply shows a considerably accurate perception. Nevertheless, a pattern is apparent. Metro supply has a higher overestimation rate than buses, i.e., walking distances are perceived as significantly shorter than they actually are. These results suggest that the transport mode is correlated with perception. This mode has the best reputation in the studied city, in contradistinction to buses, whose reputation was heavily damaged by the public transit reform occurring at the time of the research.
\end{abstract}

Keywords: Travel behavior, perceived distances, public transport, Latin America

\section{Introduction}

Public transit is a key public policy measure to tackle contemporary urban challenges to sustainability, such as mobility needs (especially for the urban poor), congestion, and pollution, among others. Despite the important role of public transport for achieving sustainable urban development in social, economic, and environmental terms, people often underuse this mode and consider it hardly adequate to meet people's mobility requirements. In some countries, it is commonplace to consider public transport as a transport mode made "for the poor." Sometimes, this affirmation derives from a relatively objective assessment of transit provision quality, which in some cities could be actually labeled "disastrous." However, it also can respond to subjective perceptions of service quality that may not be accurate. In other words, a lack of acceptance 
may respond to actual quality and functioning problems, but it also could be the consequence of bad reputation and misperception by the population.

For supply planning, the design of an adequate network and efficient exploitation is crucial. Nevertheless, to guarantee and enhance patronage, an understanding of people's travel behavior and mode choice decisions also is needed. One of the dimensions of this understanding has to do with peoples' perception of the actual supply, that is, how extensive and accurate their knowledge is regarding the concrete features of the transport supply, such as the locations of transit stops, timetables, and fare structures.

This could be the case of perceived distances to public transport stations, which the literature mentions as one of the major factors to explain mode choice (Commins and Nolan 2011; Escobar, Tudela, and González 2009; Paulley et al. 2006). Knowing how people estimate distance will matter in planning transport supply and adopting measures for increasing transit patronage. Distance estimation traditionally has been in the spatial cognition domain (Golledge and Stimson 1997) and has evolved within the psychological area. Among other objectives, it has been used to understand shopping behavior and ways of learning and building cognitive maps. It is important to note that these literature results are not categorical regarding the identification of strong predictors of distance estimation abilities. With a few exceptions (McCormack et al. 2008), specific studies that approach distance perception as a component of the evaluation of transit service quality often are not found.

The objective of this paper is to describe the gap between perceived and real distance to stations in Santiago de Chile city. This description will account for divergent patterns among modes that could be viewed as an effect of transport-specific variables. After a descriptive analysis of the information is provided, the implications for transport planning are discussed.

The remainder of the paper consists of five basic parts. The next section exposes some theoretical findings on travel behavior and mode choice decisions as well as the role of variables such as personal habits and experiences. Then, the methodological approach is explained, and the case study area of Santiago is briefly introduced. Empirical findings and results are presented, and the paper concludes by noting the need for further research and proposing some derivatives for appropriate public transport planning and policy making.

\section{Theoretical Framework}

Rietveld (2010) argues that the gap between the actual and perceived supply of public transport refers to a wide array of aspects, such as frequencies and headway regularity, travel comfort, waiting times outside of vehicles, access and egress times to and from stops, reliability and punctuality of services, vehicle occupation, and the availability of seats. In the same vein, Munizaga et al. (2008) note that waiting time outside of the vehicle and spent on mode transfers is perceived as double the actual travel time in the vehicle. Nevertheless, conventional transport demand models often neglect this fact, which affects the overestimation of actual demand and ignorance of user 
dissatisfaction. Related to this, many transport demand models are based on average door-to-door travel times, neglecting possible delays. Delays become particularly problematic for the users, if trips include missed mode transfers in a system without a regular interval timetable (Kaufmann et al. 2009; Rietveld 2010).

The importance of previous experiences of transport users in the context of actual perception and satisfaction has been the subject of many studies (Flamm, Jemelin, and Kaufmann 2008; Flamm and Kaufmann 2006; Van Acker, Van Wee, and Witlox 2010). Thus, we can distinguish between reasoned influences on travelers' behavior and mode choices, such as rational, time-related restrictions and individual preferences and attitudes, and unreasoned aspects, dealing with hardly reflected influences, such as longlasting habits and impulsiveness (Van Acker, Van Wee, and Witlox 2010).

A comprehensive explanatory approach to this issue is provided by van Acker et al. (2010), who explain travel behavior as the result of a hierarchical decision structure (Salomon and Ben-Akiva 1983), in which short-term decisions related to traveling and daily activities are based on longer-term decisions, such as residential location and lifestyle choices. On the other hand, the temporal hierarchy of these individual decisions is embedded in a specific social and societal environment, which is again conditioned by the spatial and built environment. However, different temporal and contextual levels or domains form a very complex construct of influence factors in which the resultant individual decisions on activities and traveling form the core of interest.

The importance of these two items in the transport domain have been recognized in many other studies and has produced theoretical concepts such as the motility concept by Kaufmann (2002). Kaufmann notes the individual prerequisites of competences and skills in addition to temporal and spatial access to become spatially-or sociallymobile. Moreover, a third dimension is included, which is defined as "appropriation" or simply as the transport project itself, as a result of the person's interpretation of access and skills in the context of a specific travel end. Again, the appropriation domain is mainly shaped by individual aspirations and plans and originates from the person's values, perceptions, and habits. Kaufmann (2006) underpins the high significance of habits in travel behavior according to the theoretical approach by van Acker. As an example, they mention the "rejection by principle" of specific modes such as public transport and suggest the continuing influence of a person's experiences (or lack of experiences and effective use) with these modes during childhood. This is a key variable according to our approach because mode perception could be part of the past experience necessary to estimate distances to bus or metro stations. Thus, if a transport service is evaluated as slow, inconsistent, unsafe, or imposing time costly transfers, the distance to the station also may be overestimated. In accordance with the aforementioned motility framework, when a mode has a social prejudice, this also could feed the previous experience of the traveler and may influence distance perception.

Regarding "mode reputation," note that misperception does not necessarily refer to a worse perception of an actually good supply. It might equally refer to the ignorance of effective deficiencies of transportation features due to people's good image and previous experiences with this transport system. 
In that sense, Alshalalfah and Shalaby (2007) explore the relationship between walk access distance to transit and various characteristics of the transit service and transit users in the city of Toronto, Canada. They consider quality of service to be one of the most important variables regarding willingness to walk. Indeed, they find that people in Toronto are willing to walk farther to get to routes whose frequencies are higher. The higher the frequency of the transit service, the longer people are willing to walk to access transit. It is plausible that if riders are willing to walk farther to access these routes, they also would tend to perceive the distance to a stop for one of these services as more walkable. The authors' evidence also reflects the same situation for metro services regarding bus and streetcars. People tend to walk, on average, 100 additional meters to get to the stations, even when almost 8 of $10 \mathrm{dwellers} \mathrm{have} \mathrm{transit} \mathrm{services}$ within approximately 500 meters. Our argument is consistent with this evidence. If people are willing to walk farther to metro stations than to buses or streetcars, they will conceive metro stops as being closer than they really are, either because they are willing to "spend" a physical energy surplus to use a better quality service or because the overall quality spreads to other attributes, such as walking distance to the network.

\section{Methodology}

The research question addressed in this paper is about the gap between actual and perceived distance to public transport stations. The empirical evidence describes how well people who live in the studied districts perceive the actual provision of public transport network. This description considers two basic modes: buses and metro.

The empirical evidence was gathered through a 2009 mobility survey conducted in a home-based way in 2000 households in five (of 37) districts of Santiago de Chile. These districts include the most significant centrality in the city-including the city's central business district (CBD) - and representative samples of periphery lowincome communes and affluent households sectors. By the same token, the selected territories present a wide array of scenarios regarding public transport supply, either metro or bus services. ' In each commune, approximately 400 people were surveyed. Respondents were selected according to a semi-random method (random selection of residences; selections of persons surveyed in each residence according to quotas established for age, gender, and income). The number of 400 respondents per commune provides a representative sample size per commune, with a $95 \%$ confidence level and a 0.05 confidence interval. Table 1 presents the minimum threshold to guarantee a representative sample for each district under the mentioned parameters.

\footnotetext{
${ }^{1}$ This survey was originally designed and collected for the purpose of the research work published in Witter (2012).
} 
TABLE 1.

Minimum and Definite Sample Size per Commune

\begin{tabular}{|l|c|c|c|}
\hline & Population Size & Minimum Sample Size & Definite Sample Size \\
\hline Santiago & 157,293 & 383 & 400 \\
\hline Lo Espejo & 73,006 & 382 & 400 \\
\hline Puente Alto & 305,688 & 384 & 400 \\
\hline Maipú & 299,229 & 384 & 400 \\
\hline Las Condes & 182,339 & 383 & 400 \\
\hline Total & $\mathbf{1 , 0 1 7 , 5 5 5}$ & $\mathbf{1 , 9 1 6}$ & $\mathbf{2 , 0 0 0}$ \\
\hline
\end{tabular}

The final sample population observed differed only slightly from the sample selection required, with a slight under-representation of women and low-income households and a slight over-representation of older adults. Unweighted data were used for several reasons. First, the criteria used for quotas are not necessarily the (only important) explanatory factors, and other quotas may have been equally pertinent. Second, the sensitivity analysis conducted showed that the results of the analysis using weighted and unweighted data differed only slightly and the conclusions of both analyses were the same. After all, the data were rather reliable, but some bias cannot be excluded due to a probable fatigue effect of respondents, as the survey that took 25-30 minutes in total to complete.

For all data analyses, we focused on some descriptive statistics, combined with a simple spatial analysis conducted in a geographical information system. To build the "dependent" variable, it was necessary to overlap two measures of distance: the perceived distance and the actual distance. The former-perceived walking distance to metro and bus stops-was revealed through a question about each mode's station availability within approximately 400 meters (or "within 4 or 5 minutes walking"). The answers referring to the perceived supply were superposed with the real supply measured using GIS (aerial distance to metro stations and bus routes). Then, a new variable was built with three categories: "correct estimation," considerable "overestimation," and "underestimation" of walking distances. ${ }^{2}$

\section{The Case of Santiago de Chile}

The metropolitan area of Santiago de Chile comprises 37 boroughs or municipalities with approximately 5.5 million inhabitants (2002 Census), spread over a surface of 76,000 hectares. Morphologically, the city is characterized by a rather mono-centricradial structure with the traditional CBD in the central (homonymous) municipality of Santiago-Centro and radial transport axes, connected by a privately-run ring road highway. In addition, in the last decade, a second economical center has emerged in the affluent cone of wealth in the eastern part of the city, which has gained increasing economic dominance over the traditional CBD (Witter and Hernández 2012).

\footnotetext{
${ }^{2}$ A 100-meter misperception was accepted. Thus, if a person answered that he/she does not have a bus stop within $\mathbf{4 0 0}$ meters, to be classified as "underestimating" supply, the stop should be within a 300meter area of influence. Conversely, to "overestimate," a person should declare the availability of buses but must be at least 500 meters from the closest route.
} 


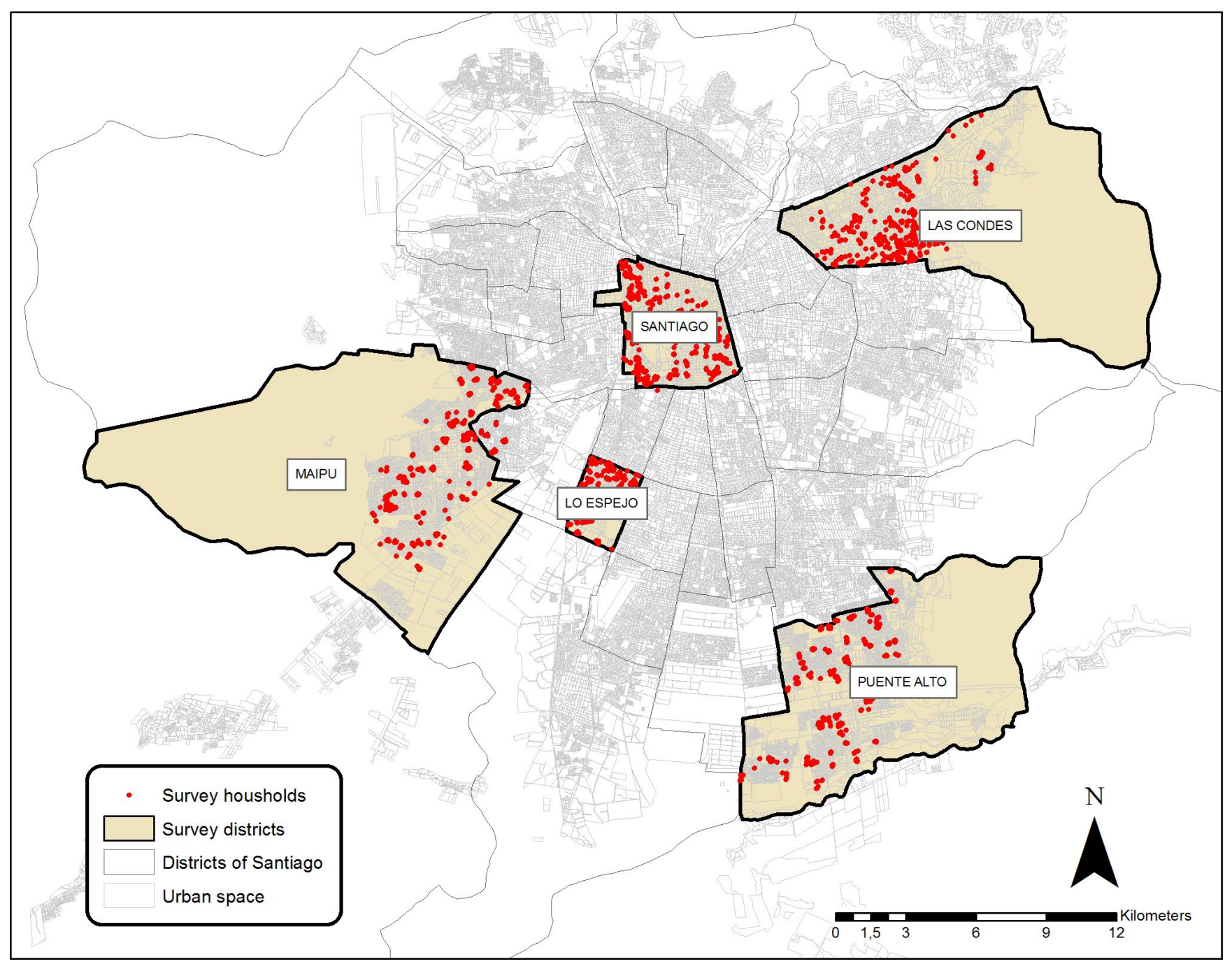

FIGURE 1. Surveyed households and location of Santiago's districts

Figure 2 shows the public transport network, which encompasses a vast bus network with trunk services composed of high-capacity articulated buses that serve routes along the city and feeder services that extend to local areas. It also includes subway services (5 lines), which operate under a tariff union scheme with buses. The bus system went through a serious crisis after the implementation of a new reregulated system known as Transantiago, an ambitious failed project aimed at providing high-quality, cost-effective services that, after an abrupt start, immediately provoked actual chaos in the city (for information on the Transantiago project, see Witter and Hernández 2012; Figueroa and Orellana 2008; Muñoz and Gschwender 2008a; Muñoz and Gschwender 2008b; Witter 2012). This is a reason why bus systems are very unpopular with the population. In contrast, the metro enjoys a very positive reputation. The tariff union brought many new users-one of the most positive effects of the Transantiago project - that generated very high metro occupancy, which caused it to become much more crowded than usual, especially during peak hours. However, this mode is still evaluated as providing fast and reliable service. 


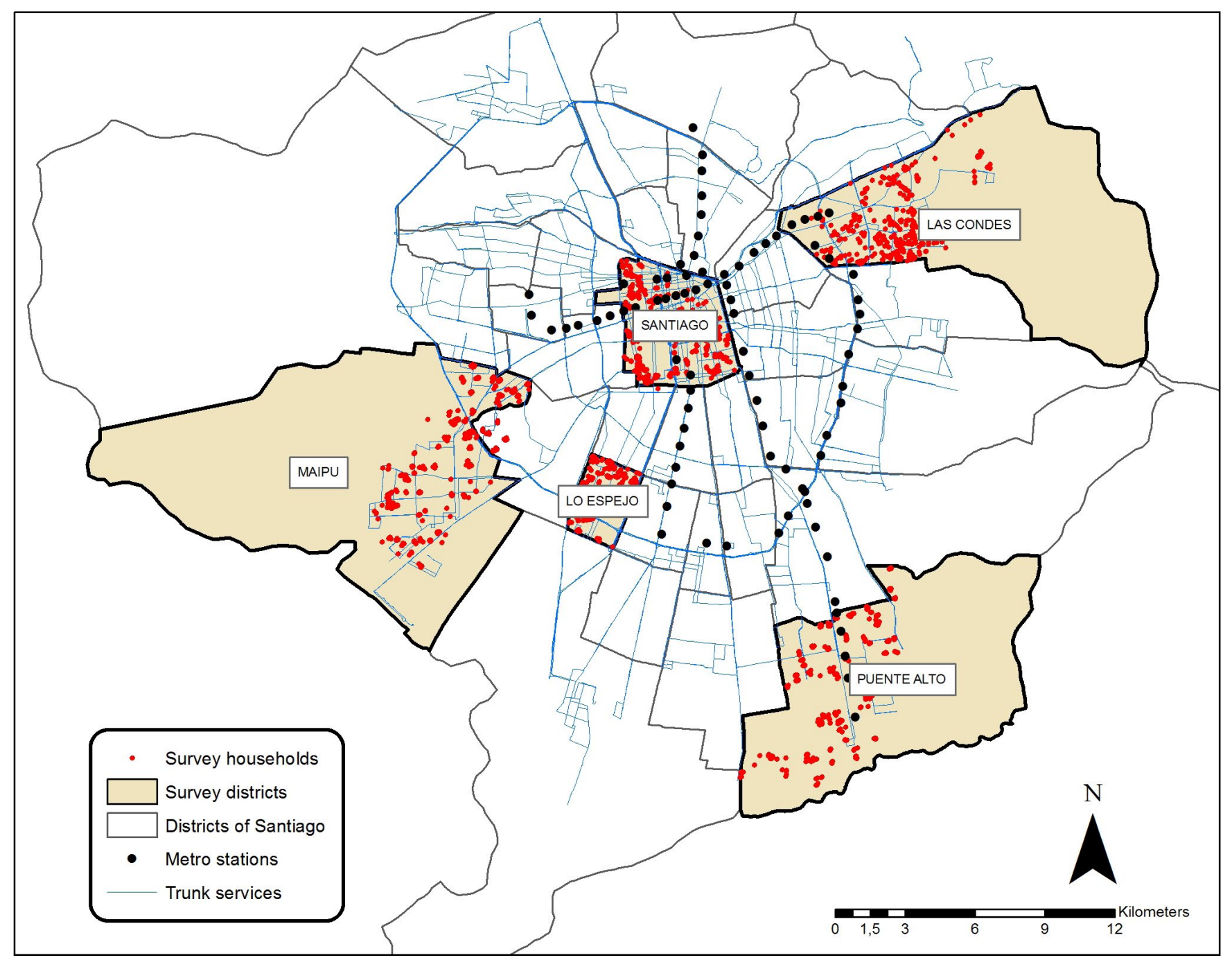

FIGURE 2. Surveyed households and locations of Santiago's districts and transit networks (trunk services and metro stations)

\section{Results: Perceived and Actual Distances}

To begin the empirical analysis, the actual and perceived distances to the network from households in the survey sample are described. First, in Table 2, the actual distances to trunk bus routes and metro stations are depicted. In the case of trunk routes, the network extension and density is extremely high. As a result, in four of the five studied districts, at least $92 \%$ of the interviewee households have a trunk route within approximately 400 meters. Puente Alto commune constitutes an exception, with only one-third of the households in the sample being located within the service area. 
TABLE 2.

Network Coverage and Average Actual Distance to Network by District and Mode

\begin{tabular}{|l|c|c|c|c|}
\hline \multicolumn{1}{|c|}{ District } & $\begin{array}{c}\text { Bus (Trunk) } \\
\text { Route within } \\
\mathbf{4 0 0} \mathbf{m}(\mathbf{a})\end{array}$ & $\begin{array}{c}\text { Average } \\
\text { Euclidian } \\
\text { Distance to } \\
\text { Trunk Route (b) }\end{array}$ & $\begin{array}{c}\text { Metro Station } \\
\text { within } \mathbf{4 0 0} \mathbf{~ m} \\
\text { (a) }\end{array}$ & $\begin{array}{c}\text { Average Euclidian } \\
\text { Distance to Metro } \\
\text { Station (b) }\end{array}$ \\
\hline Las Condes & $91.9 \%$ & 202 & $3.5 \%$ & 3,073 \\
\hline Lo Espejo & $96.0 \%$ & 172 & $0 \%$ & 2,869 \\
\hline Maipú & $95.3 \%$ & 166 & $0 \%$ & 6,908 \\
\hline Puente Alto & $31.2 \%$ & 629 & $2.9 \%$ & 1,958 \\
\hline Santiago & $99.9 \%$ & 56 & $20.2 \%$ & 908 \\
\hline
\end{tabular}

(a) As a percentage of households

(b) In meters

As with the service area, the average distance to a trunk route also reflects that the network is very dense with high coverage. In three districts, the average distance is between approximately 160 and 200 meters. At the highest endpoint, Puente Alto has more than 600 meters of average distance, whereas Santiago has the denser network supply, with the average distance being approximately 56 meters from each household in the sample. Note that Santiago is still the most important urban centrality in which governmental, economic, and political resources locate. Moreover, a relevant portion of urban routes-especially trunk routes-pass through this district or have their destination there.

Regarding the metro network supply, it is almost the opposite situation of the bus network. Indeed, it is clear that the metro network has a lower density and is not spread through the city as in other urban agglomerations. Two districts did not have any households within 400 meters when the data were collected. ${ }^{3}$ In Puente Alto and Las Condes, only approximately 3\% of households are within a 400-meter buffer of any metro station. Santiago is the only district in which a fairly dense metro network exists. Similar to the bus network density, its central role in urban life explains this fact. Nevertheless, the percentage of households is still low (20\%).

Given these data, the first limitation arises because some scenarios will have to be discarded. For logical reasons, underestimation of metro services is not found in Lo Espejo and Maipu, and it will be difficult to find in Las Condes and Puente Alto as well. For the same reasons, it is unlikely that overestimation of bus supply will be found for any districts except Puente Alto. Having said that, in the following tables and charts, both supply measures-actual and perceived-are depicted.

Figure 3 shows the overall percentage of correct estimation, overestimation and underestimation of metro station and trunk bus routes. It must be noted that these figures include the five districts, which, as shown before, are very different regarding each mode's actual supply. Despite these differences, the relevant fact to note is that at least 8 of 10 persons "correctly" answer the question about bus and metro supply in his neighborhood. The data indicate that people are aware of the existence or absence

\footnotetext{
${ }^{3}$ The extension of one of the metro routes currently reaches the district of Maipu.
} 
of public transportation supply and are able to estimate distance regarding a given distance threshold. As expected, the percentage of metro overestimation is higher than that for buses because the former network extension is smaller than the latter. This fosters the potential for overestimation when answering the question.

FIGURE 3.

Overlap between actual and declared distances*

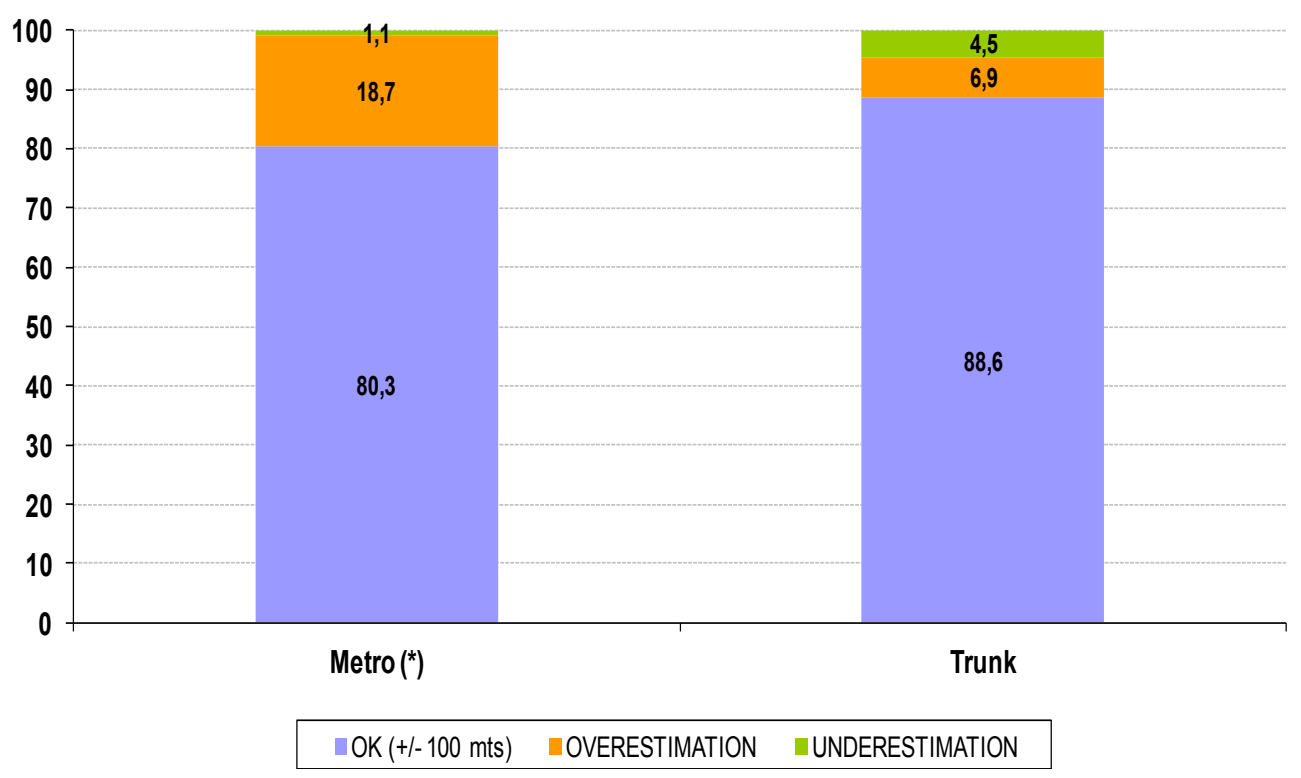

*Only communes with metro service.

To some extent, this indicates that people are responsive to actual supply. Accordingly, it could be argued that they will be responsive to changes in quality of the serviceat least they will be responsive in terms of awareness of these changes, regardless of changes in their behavior that it could cause.

Table 3 analyzes the gap between actual and perceived supply for each commune. By doing so, it is possible to control for the different actual supply mentioned above. For the three districts in which some type of metro supply exists, the availability of metro services is very often overestimated, which means that distances to the metro network are underestimated.

TABLE 3.

Overlap between Actual and Declared Distances by Mode

\begin{tabular}{|l|c|c|c|c|}
\hline \multirow{2}{*}{ District } & \multicolumn{2}{|c|}{ Metro } & \multicolumn{2}{c|}{ Trunk Route } \\
\cline { 2 - 5 } & Overest. Supply & Underest. Supply & Overest. Supply & Underest. Supply \\
\hline Las Condes & $6.5 \%$ & $0.3 \%$ & $2.6 \%$ & $1.5 \%$ \\
\hline Lo Espejo & 0 & 0 & $0.8 \%$ & $6.9 \%$ \\
\hline Maipu & $3.3 \%$ & 0 & $1.6 \%$ & $6.8 \%$ \\
\hline Puente Alto & $14.4 \%$ & $1.1 \%$ & $19.4 \%$ & $3.6 \%$ \\
\hline Santiago & $39.1 \%$ & $1.8 \%$ & 0 & $4.2 \%$ \\
\hline
\end{tabular}


For all of the districts, the underestimation of metro supply is very low. As previously mentioned, it is senseless to pay attention to the underestimation figures of the metro in communes in which only $3 \%$ of the interviewees live within 400-meter walking distance of a station. ${ }^{4}$ Nonetheless, the underestimation is also marginal in the case of Santiago district, in which the actual service is relatively extended.

Regarding bus services, once again it is pointless to consider overestimation in those districts with almost full availability within a 400-meter walking distance. In the case of Puente Alto (with only $31 \%$ availability), however, overestimation is registered. Indeed, more than $19 \%$ of people from this neighborhood affirm that they have access to the bus supply closer than they really do. Moreover, the underestimation figure is the second lowest of the five districts.

Do the figures in this table mean that the overestimation of metro or bus service is just an artifact of the actual supply? In other words, do people overestimate (when the network is not as extensive as the metro) or underestimate (when the network is as extensive as the bus network) as an automatic reflection? It is mathematically impossible to collect overestimations if $100 \%$ of people live within a given walking distance under the adopted distance threshold. Nevertheless, we posit that the overestimation is different between metro and bus services. In fact, the former seems to be more frequently overestimated than the latter.

To illustrate this point, in the remainder of the paper, the focus is on the two districts for which a comparison seems reasonable. The case of Puente Alto and Santiago are adequate because both have metro services (minimal in the case of Puente Alto) and low coverage of buses, thus providing the potential for comparison between modes. Unfortunately, the built environments in these communes are rather different. Santiago is a typical urban "walkable" setting with high dwelling density and mixed land use. On the contrary, Puente Alto has less density and mixed land use.

Table 4 synthesizes the amount of overestimation regarding actual supply for the cases in which it exists: bus and metro in Puente Alto and metro in Santiago. The upper side of the table presents the data on actual and perceived distances to both networks. The overestimation as a percentage of the actual supply is higher in the case of metro service, regardless of the district. In Puente Alto, the "total" metro supply is more than five times the actual one. This means that despite the very limited service within a 400meter walking distance, $14 \%$ of the population perceives that they can reach the metro service within that distance. In the case of Santiago, even when the percentage of actual metro service is $20 \%$, the overestimation still almost double, reaching a "total supply" of almost three times the actual service.

\footnotetext{
${ }^{4}$ To be classified as underestimating the service, the person should have answered "no availability" regarding having a station or route within 300 meters of his dwelling. This decision was made to be more categorical about the misperception. Nevertheless, the difference between this measure and the one taken to determine the precise distance of 400 meters is minimal.
} 


\begin{tabular}{|c|c|c|c|c|}
\hline \multirow{5}{*}{$\begin{array}{r}\text { TABLE } 4 . \\
\text { Actual and Total Supply } \\
\text { including Perception } \\
\text { Correction, Metro and Trunk } \\
\text { Bus Service, Santiago and } \\
\text { Puente Alto }\end{array}$} & & $\begin{array}{c}\text { Puente Alto } \\
\text { Metro }\end{array}$ & $\begin{array}{c}\text { Santiago } \\
\text { Metro }\end{array}$ & $\begin{array}{l}\text { Puente Alto } \\
\text { Trunk Buses }\end{array}$ \\
\hline & (a) Actual supply & 3 & 20 & 31 \\
\hline & (b) Overestimation & 14 & 39 & 19 \\
\hline & (c) Underestimation & 1 & 2 & 4 \\
\hline & "Total" supply $(a+b-c)$ & 16 & 57 & 46 \\
\hline
\end{tabular}

Meanwhile, for the case of bus overestimation (Table 5), the figures are much lower than those for the metro. The "total supply" in this case is approximately 1.5 times the original one. Thus, it is possible to speculate that the metro as a mode tends to maximize supply overestimation.

TABLE 5.

Actual Average Distances for People who Overestimate Transportation Supply, Metro and Trunk Bus Service, Santiago and Puente Alto

\begin{tabular}{|l|c|c|c|}
\hline & $\begin{array}{c}\text { Puente Alto Metro } \\
(\mathrm{m})\end{array}$ & $\begin{array}{c}\text { Santiago Metro } \\
(\mathbf{m})\end{array}$ & $\begin{array}{c}\text { Puente Alto Trunk Buses } \\
(\mathrm{m})\end{array}$ \\
\hline Mean & 1,076 & 1,103 & 776 \\
\hline Quartile 1 & 669 & 765 & 603 \\
\hline Median & 878 & 1,091 & 778 \\
\hline Quartile 3 & 1,325 & 1,368 & 922 \\
\hline
\end{tabular}

The data in the Table 5 refer to the actual distances to the metro and bus services from the residence of people who overestimate each mode supply. In short, people from Puente Alto who answered yes to the question "Is there a metro station within 400 meters" even though no station exists within a 500-meter area is, on average, actually 1076 meters from the closest metro station. To some extent, this distance sets a threshold of "willingness to walk" to a metro station because they perceive it as a very short one.

It is interesting that metro "overestimators" are, on average, approximately 1,100 meters away from the closest station because the overestimations of buses in Puente Alto are notably lower, at 780 meters. One of the reasons is that trunk routes in Puente Alto are, on average, closer than metro stations. Nevertheless, the relevant question is if trunk routes had longer distances, would people who overestimate increase that threshold? By the same token, it is plausible that people would not underestimate walking distance to the metro after 700 meters, but they did so. Those questions will remain unanswered, but evidence suggests that the metro's willingness-to-walk threshold (i.e., perceive as longer than a 400-meter walking distance) is higher than the buses' threshold.

\section{Concluding Remarks}

People have a relatively accurate perception of the transport supply around their residence location. In general terms, when perceived supply does not match the actual supply, the bias is towards an overestimation of the actual supply by underestimating walking distance to the metro station or the bus stop. 
In particular, distances to metro stops are perceived to be shorter than they are in reality. A generally very good image of this transportation mode, particularly in comparison with less efficient bus services, may have an important influence on people's underestimation of distances and overestimation of actual supply quality. With very limited network coverage, metro services have a greater effect on perceived supply. Even when this does not necessarily mean that people will switch from private to public transit, one plausible explanation is that when a good image exists, people will be prone to walk farther to use this service because they perceive the distance as "walkable."

A substantial discussion can take place. First, in contradistinction to some pieces of literature, in this case, people do not tend to systematically overestimate distances. On the contrary, regardless of the mode, when the actual supply was limited (such as the metro for all of the districts or buses for Puente Alto), a portion of people overestimated actual supply, assuming that the network was within $\mathbf{4 0 0}$ meters in cases in which it was much farther than that. In the case of the metro, the threshold for what people consider walkable distance was higher than for buses.

This evidence could support Lee's (1970) "decreasing factor" of overestimation because for very long distances, the proportional overestimation factor decreases. The metro service location was systematically farther than bus routes. That could be a reason why people keep declaring the existence of supply within 400 meters even when the closest station is more than 900 meters away.

Finally, even when data do not help to confirm it, the quality of the service as a factor that fosters overestimation of supply remains a plausible hypothesis. Empirical evidence of this paper is in line with Alshalalfah and Shalaby's (2007) findings, which show that people's willingness to walk is higher for buses with more frequent schedules. There are two possible mechanisms that drive "quality effect" on supply perception. The first is Flamm and Kaufmann's (2006) "rejection by principle" (or "compliance by principle," we would add) of specific modes such as buses. The second is a more rational argument that could be part of the reasoned influences on traveler behavior and mode choices (Van Acker, Van Wee, and Witlox 2010). Considering that the metro is a faster public service (and more reliable, in the case of Santiago de Chile), people might make a trade-off between time in the vehicle and time walking to the station. In this case, the individual should conceive of the trip as a unit.

The results of this paper are a description based on data with several limitations. The gap is calculated using fixed thresholds $(400 \mathrm{~m})$ and without considering the stations actually used by the respondents. Nevertheless, the empirical evidence is robust enough to suggest that mode is a key variable to understanding distance estimation to the stations. It is clear that there are several mode characteristics other than distance that influence how far or close people perceive a given mode station to be. In that sense, the paper provides strong motivation to go further in the field of distance estimation in the context of transport studies. 


\section{References}

Alshalalfah, B. W., and A. S. Shalaby. 2007. "Case Study: Relationship of Walk Access Distance to Transit with Service, Travel, and Personal Characteristics." Journal of Urban Planning and Development, 133(2): 114-18. doi: 10.1061/(ASCE)07339488(2007)133:2(114).

Bafna, S. 2003. "Space Syntax: A Brief Introduction to Its Logic and Analytical Techniques." Environment \& Behavior, 35(1): 17-29. doi: 10.1177/0013916502238863.

Commins, N., and A. Nolan. 2011. "The Determinants of Mode of Transport to Work in the Greater Dublin Area." Transport Policy, 18.

Crompton, A. 2006. "Perceived Distance in the City as a Function of Time." Environment and Behavior: $173-82$.

Escobar, M., A. Tudela, and A. González. 2009. “Estudio del Papel de Aspectos Sicológicos, de Hábito y Contexto en la Elección de Modo." Buenos Aires: Trabajo presentado en el XV CLATPU (Congreso Latinoamericano de Transporte Público Urbano).

Figueroa, O., and A. Orellana. 2008. "Transantiago: Gobernabilidad E Institucionalidad." EURE 33.

Flamm, M. 2003. “Compréhendre Le Choix Modal - Les Déterminants de Pratique Modale et Des Représentations Individuelles Des Moyens de Transport." Thèse No. 2897. Lausanne: EPFL-press.

Flamm, M., C. Jemelin, and V. Kaufmann. 2008. "Travel Behaviour Adaptation Processes during Life Course Transitions. A Methodological and Empirical Study Using a Person-Based GPS Tracking System." Lausanne: Laboratoire de Sociologie Urbaine (LASUR).

Flamm, M., and V. Kaufmann. 2006. “Operationalising the Concept of Motility: A Qualitative Study." Mobilities, 1: 167-89.

Golledge, R. G., and R. J. Stimson. 1997. Spatial Behaviour : A Geographic Perspective. New York: The Guilford Press.

Hillier, B., and S. lida. 2005. "Network Effects and Psychological Effects: A Theory of Urban Movement." Delft: Paper presented at the 5th International Space Sintax Symposium, June 17, 2013.

Jemelin, C., V. Kaufmann, J. Barbey, and T. Klein. 2006. “Politiques de Transport et Inégalités Sociales D’accès - Analyse Comparative de Huit Agglomérations Européennes." Rapport de recherche PREDIT. EPFL Press. Lausanne.

Kaufmann, V. 2002. Re-Thinking Mobility. Contemporary Sociology. Aldershot (England) and Burlington (USA): Ashgate.

Kaufmann, V. 2003. L'automobile Au Carrefour de Snos Contradictions. Société Suisse des Ingénieurs et des architectes SIA. tRACES 10. 
Kaufmann, V., R. Witter, L. Stàhli, and W. Stohler. 2009. "Etude de la Pertinence du Cadencement Entre Offre et Demande." Paris: Technical report for Réseau Ferroviaire Français RFF.

Kim, Y. 2001. "The Role of Spatial Configuration in Spatial Cognition." Proceedings of the Third Space Syntax Symposium, Georgia Institute of Technology, Atlanta.

Kim, Y. O., and A Penn. 2004. "Linking the Spatial Syntax of Cognitive Maps to the Spatial Syntax of the Environment." Environment \& Behavior, 36(4): 483-504. doi:10.1177/0013916503261384.

Lee, T. 1970. "Perceived Distance as a Function of Direction in the City." Environment and Behavior, 2: 40-51.

Marquez Perez, J. 2004. “I Curso de Experto Universitario en Sistemas de Información Geográfica." Sevilla: Apuntes de Clase. http://sig.utpl.edu.ec/sigutpl/biblioteca/ manuales/REDES_ver_56.pdf.

McCormack, G. R., E. Cerin, E. Leslie, and L. Du Toit. 2008. "Objective versus Perceived Walking Distances to Destinations: Correspondence and Predictive Validity." Environment and Behavior: 401-25.

Munizaga, M., S. Jara-Diaz, P. Greeven, and C. Bhat. 2008. "Econometric Calibration of the Joint Time Assignment-Mode Choice Model." Transportation Science, 42(2): 20819. doi: $10.1287 /$ trsc.1080.0231.

Muñoz, J. C., and A. Gschwender. 2008a. "Transantiago: A Tale of Two Cities." Research in Transportation Economics, 22: 45-53.

Muñoz, J. C., and A. Gschwender. 2008b. Transantiago: The Fall and Rise of a Radical Public Transport Intervention. Santiago de Chile: MIMEO.

Paulley, N., R. Balcombe, R. Mackett, H. Titheridge, J. Preston, M. Wardman, J. Shires, and P. White. 2006. "The Demand for Public Transport: The Effects of Fares, Quality of Service, Income and Car Ownership." Transport Policy, 13: 295-306.

Rietveld, P. 2010. "Six Reasons Why Supply-Oriented Indicators Systematically Overestimate Service Quality in Public Transport." Transport Reviews, 25: 319-28.

Sadalla, E., and K. Staplin. 1980. "The Perception of Traversed Distance, Intersections." Environment and Behavior, 12: 167-82.

Salomon, I., and M. Ben-Akiva. 1983. "The Use of the Life-Style Concept in Travel Demand Models." Environment and Planning A, 15(5): 623-38. doi: 10.1068/a150623.

Tressider, M. 2005. “Using GIS to Measure Connectivity: An Exploration of Issues." Field Area paper, School of Urban Studies and Planning, Portland State University.

Tversky, B. 2003. "Structures of Mental Spaces: How People Think about Space." Environment \& Behavior, 35(1): 66-80. doi: 10.1177/0013916502238865.

Ureta, S. 2009. “Manejando por Santiago. Explorando el Uso de Automóviles por Parte de Habitantes de Bajos Ingresos desde Una Óptica de Movilidad Sustentable." EURE XXXV: 71-93. 
Van Acker, V. B. van Wee, and F. Witlox. 2010. "When Transport Geography Meets Social Psychology: Toward a Conceptual Model of Travel Behaviour." Transport Reviews, 30 (2): 219-40. doi: 10.1080/01441640902943453.

Witter, Regina. 2012. "Public Urban Transport, Mobility Patterns and Social Exclusion: The Case of Santiago de Chile." Doctoral thesis, Laboratoire de Sociologie Urbaine (LaSUR).

Witter, R., and D. Hernández. 2012. "Santiago de Chile and the Transantiago: Social Impact." In Technologies and Innovations for Development, Jean-Claude Bolay, Magali Schmid, Gabriela Tejada, and Eileen Hazboun (eds.). Paris: Springer Paris. http://www.springerlink.com/index/10.1007/978-2-8178-0268-8_4.

Zimring, C., and R. C. Dalton. 2003. "Linking Objective Measures of Space to Cognition and Action." Environment \& Behavior, 35(1): 3-16. doi: 10.1177/0013916502238862.

\section{About the Authors}

Diego Hernández, PH.D. (dhernandez@correo.ucu.edu.uy) is a sociologist and Assistant Professor in the Social and Political Sciences Department of Catholic University of Uruguay. His research focuses on transport and society, particularly transport and social exclusion and equity (affordability and spatial accessibility) and the attitudinal and subjective dimensions of travel behavior and daily mobility.

RegiNA WitTeR, PH.D. (pikkumyy@gmx.de) is a spatial planning and transport engineer. After several years conducting transport research in the fields of travel behavior, transport inequalities, and social exclusion, she currently works as a transport engineer for the regional government of Lausanne-Morges, Switzerland. 